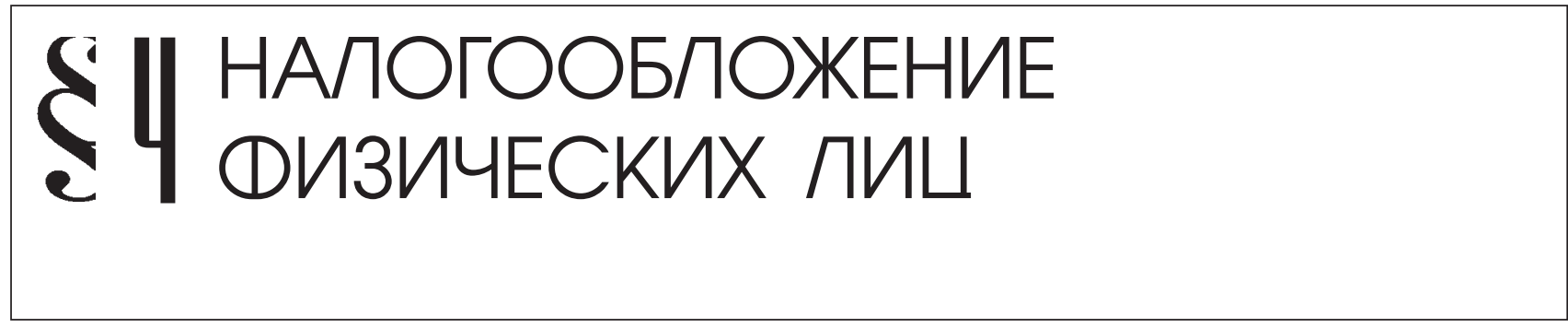

Пылаева А.В.

\title{
О НАЛОГОВОЙ НАГРУЗКЕ НА ФИЗИЧЕСКИХ ЛИЦ ПО НАЛОГУ НА ОБЪЕКТЫ ЖИЛОГО ФОНДА, ИСЧИСЛЕННОМУ НА ОСНОВЕ КАДАСТРОВОЙ СТОИМОСТИ
}

Аннотация: Планируемое введение налога на недвижимость на основе кадастровой стоимости не должно привести к неконтролируемому существенному изменению налоговой нагрузки, что вполне возможно вследствие существенного отличия кадастровой стоимости от инвентаризационной. В связи с этим возникает необходимость проведения анализа социально-экономических последствий введения новой модели налога на основе результатов кадастровой оценки объектов капитального строительства, впервые проведенной в Российской Федераџии в 2011-2012 г2. Такой анализ позволит определить параметры налогообложения, соответствующие оптимальному распределению налоговой нагрузки. Оиенка налоговой нагрузки по объектам недвижимости жилого назначения в Калужский области и Республике Татарстан, проведенная в рамках выполнения работ проекта МБРР «Анализ сочииально-экономических последствий введения налога на недвижимость», выявила необходимость установления социального налогового вычета по площуади объекта налогообложения. Налоговый вычет в настоящее время введен в конструкцию нового налога. С его учетом на примере Нижегородской области автор оценил налоговую нагрузку на физических лиц, подавляющее большинство которых являются собственниками и плательщиками налога на жилую недвижимость, сделал вывод о категории налогоплательщиков, для которых она будет чрезмерной, предложил рекомендации по ее смягчению.

Review: The planned introduction of the immovable property tax calculated based on cadastral value should not lead to the uncontrolled considerable changes in the tax burden, while this situation is quite possible due to the considerable difference between the cadastral and inventory values. Due to the above-mentioned reasons, there is a need to analyze social and economic consequences of the introduction of the new tax model based upon the results of cadastral evaluation of the capital construction objects, which was held for the first time in the Russian Federation in 2011-2012. Such an analysis shall allow establishing the parameters for the taxation with an optimum spread of tax burden. Evaluation of tax burden for 
the capital construction housing objects in the Kaluga region and the Republic of Tatarstan took place within the framework of the IBRD project "Analysis of Social and Economic Consequences of Imposing Property Tax", and it has shown the need to provide social tax deduction based upon the area of taxation object. The tax deduction is currently included into the framework of the new tax. Taking it into account and using Nizhegorodskiy region as an example, the author evaluated the tax burden on physical persons, most of whom are owners and payers of taxes for housing, then the author made a conclusion on the category of taxpayers, for whom it shall be excessive, and offered to mitigate it.

Ключевые слова: недвижимость, налогообложение недвижимости, объекты капитального строительства, налоговая ставка, налоговая база, налоговые вычеты, налоговая нагрузка, кадастровая стоимость, инвентаризационная стоимость, модель налога Keywords: immovable property, immovable property taxation, capital construction objects, tax rate, tax basis, tax deduction, tax burden, cadastral value, inventory value, tax model.

\section{Введение}

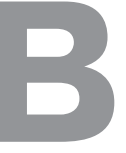

ведение налога на недвижимость на основе рыночной стоимости вот уже 10 лет является стратегической целью налоговой политики Российской Федерации. Подготовка к этому началась в 1997 году в России с проведения эксперимента в Великом Новгороде и Твери для отработки концепции введения налога на недвижимость и механизма перехода к налогообложению на основе оценки объектов недвижимости по рыночной стоимости.

Так как новый налог в действующей редакции Налогового кодекса РФ не был предусмотрен, его основные характеристики были определены Федеральным законом №110-Ф3 от 20 июля 1997 г. «О проведении эксперимента по налогообложению недвижимости в городах Великом Новгороде и Твери» ${ }^{1}$. В качестве объекта налогообложения рассматривался единый

\footnotetext{
${ }^{1}$ Российская Федерация. Законы. О проведении эксперимента по налогообложению недвижимости в городах Великом Новгороде и Твери: Федеральный закон от 20.07.1997 N 110-Ф3
}

объект недвижимости - земельный участок и улучшения, поэтому обязательным условием эксперимента являлось формирование единого объекта налогообложения - земли плюс улучшений - как объекта права и объекта налогообложения. Такой подход к определению объекта налогообложения сложился под воздействием международного опыта, но без учета российской практики правового определения объекта недвижимости, что впоследствии и не позволило вовлечь достаточное количество объектов недвижимости и их правообладателей в эксперимент.

Эксперимент был завершен в 2004 году, в Великом Новгороде в нем приняли участие 44 юридических лица ${ }^{2}$, в Твери эксперимент не состоялся. Примечательно, что в перечень планируемых работ вхо-

\footnotetext{
${ }^{2}$ Налог на недвижимость: результаты эксперимента в Великом Новгороде и Твери [Электронный peсурс]: стенограмма «круглого стола» Комитета Совета Федерации по бюджету, 26 янв. 2006 г. // Государственный научно-исследовательский институт системного анализа Счетной палаты Российской Федерации : офиц. сайт. - URL: http://www.niisp.ru/ News/Events/art67.
} 
дило, в том числе, намерение проведения анализа последствий введения налога на недвижимость. Но в результате проведения эксперимента была выявлена проблема определения объекта налогообложения, правовое формирование единого объекта недвижимости из земельной и имущественной составляющих. По этой причине не был введен единый налог для владельцев жилой (квартир, домов) и нежилой (кафе, магазинов, парикмахерских и т.д.) недвижимости, не было материала для проведения анализа последствий введения налога на недвижимость ${ }^{3}$.

Определение основных элементов налога и оценка налоговой нагрузки в проекте МБРР «Анализ социально-экономических последствий введения налога на недвижимость".

Следующим знаковым этапом в подготовке введения налога на недвижимость стал проект Международного Банка Реконструкции и Развития «Разработка и тестирование системы кадастровой (массовой) оценки недвижимости в Российской Федерации». Он проходил совершенно в иных условиях. К этому времени изменилось понимание объекта налогообложения - в российской законодательной базе и практике правового учета объектов недвижимости единые объекты недвижимости отсутствовали, был введен налог на земельные участки на основе кадастровой стоимости, оставалось подготовить условия для введения налога на объекты капитального строительства на основе их рыночной стоимости.

\footnotetext{
${ }^{3}$ Шевчук, Л. А. Отчет о результатах эксперимента по введению налога на недвижимость в г. Твери [Электронный ресурс] / Л. А. Шевчук. - URL: http:// old.tchirkounov.ru/articles/print.php?id=210.
}

Эксперимент проходил Кемеровской, Калужской, Тверской областях, ре спублике Татарстан; в качестве потенциальных объектов налогообложения рассматривались около 4 миллионов объектов капитального строительства ${ }^{4}$. В результате анализа перечня объектов капитального строительства было выявлено, что подавляющее большинство объектов оценки (около 90 \%) составляют объекты жилого фонда, в том числе квартиры (около 65\%) и индивидуальные жилые дома (около 25\%). Впоследствии, в 2012 году, эта статистика подтвердится в целом по России - объекты капитального строительства жилого фонда в составе объектов капительного строительства, учтенных в Государственном кадастре недвижимости, составляют $83 \%$. ${ }^{5}$.

Рыночная стоимость объектов капитального строительства достаточно высока, поэтому очень важно было оценить налоговую нагрузку на физических лиц, подавляющее большинство которых являются плательщиками налога на жилую недвижимость.

Эта задача решалась в рамках проекта Международного Банка Реконструкции и Развития «Анализ социально-экономических последствий введения налога на недвижимость» в 2010 г. ${ }^{6}$.

\footnotetext{
${ }^{4}$ Пылаева A.B. Разработка и тестирование системы кадастровой оценки недвижимости в Российской Федерации» // Земля Беларуси.- 2012. - № 1. C. 20-24

5 Пылаева A.B. Налог на недвижимость: какими должны быть основные параметры // Налоговая политика и практика. - 2013. - № 7. - С. 27-30.

${ }^{6}$ Безруков В.Б. Дмитриев М.Н., Пылаева А.В. Налогообложение и кадастровая оценка недвижимости. Монография. Н.Новгород : ННГАСУ, 2011. -153 c..
} 
Прообраз конструкции основных элементов налога сложился в процессе выполнения этого проекта. Вследствие существенного превышения планируемой налоговой базы (кадастровой стоимости) над текущей налоговой базой (инвентаризационной стоимости) было предложено в новой конструкции налога предусмотреть механизм налоговых вычетов для физических лиц.

Оценка налоговой нагрузки была проведена в Калужской области и республике
Татарстан, она выявила ее чрезмерность и необходимость установления вычетов по площади объекта налогообложения ${ }^{7}$ (табл. 1.) Для определения оптимального размера налоговых вычетов были предложены различные варианты численных значений вычетов- от нуля до 50 кв.м. площади объектов налогообложения, для каждого из которых исследовано распределение налогового бремени по социальным группам налогоплательщиков ${ }^{8}$.

Таблицча 1.

Оценка планируемой налоговой нагрузки по объектам недвижимости жилого назначения в Калужский области и Республике Татарстан в 2009 г.

\begin{tabular}{|c|c|c|c|c|}
\hline $\begin{array}{l}\text { Доля налоговых пла- } \\
\text { тежей по объектам }\end{array}$ & \multicolumn{2}{|l|}{$\begin{array}{l}\text { Калужская } \\
\text { область }\end{array}$} & \multicolumn{2}{|l|}{$\begin{array}{l}\text { Республика } \\
\text { Татарстан }\end{array}$} \\
\hline $\begin{array}{l}\text { месячной заработной } \\
\text { плате } \\
\text { (2009 г. ) }\end{array}$ & мин, \% & мах \% & мин\% & $\max \%$ \\
\hline $\begin{array}{l}\text { - для малоимущих } \\
\text { граждан }\end{array}$ & $\begin{array}{l}0,11 \% \text { (Лю- } \\
\text { диновский } \\
\text { район) }\end{array}$ & $\begin{array}{l}17,30 \% \\
(г . \text { Обнинск). }\end{array}$ & $\begin{array}{l}1,39 \% \\
\text { (г. Набереж- } \\
\text { ные Челны) }\end{array}$ & $\begin{array}{l}39,47 \% \\
\text { (Арский } \\
\text { район). }\end{array}$ \\
\hline $\begin{array}{l}\text { - для граждан иных } \\
\text { категорий }\end{array}$ & $\begin{array}{l}0,55 \%(\text { Ба- } \\
\text { бынинсикий } \\
\text { район })\end{array}$ & $\begin{array}{l}9,18 \% \\
\text { (Людиновский } \\
\text { район) }\end{array}$ & $\begin{array}{l}1,18 \%(\text { Мен- } \\
\text { делеевский } \\
\text { район })\end{array}$ & $\begin{array}{l}7,06 \% \\
\text { (Арский } \\
\text { район). }\end{array}$ \\
\hline
\end{tabular}

7 Анализ социально-экономических последствий введения налога на недвижимость на основе результатов массовой оценки недвижимости: дайджест контракта МБРР № 52-CA-IIIA-QBS [Электронный ресурс] 2011 г. / - URL: http://www.ecsro.ru/uploads/import/ doc_roseestr/2773665/1.pdf

${ }^{8}$ Безруков В.Б. Социальные аспекты налога на недвижимость. // Налоговая политика и практика. - 2012. - № 7.- С.12-16. 
DOI: $10.7256 / 1812-8688.2013 .7 .9345$

При цитировании этой статьи сноска на doi обязательна

\section{Налоги и налогообложение - №7(109)• 2013}

В 2012 году впервые была проведена кадастровая оценка объектов капитального строительства, результаты которой подтвердили высокий уровень кадастровой стоимости во всех субъектах Российской Федерации ${ }^{9}$ (табл. 2)
Из таблицы 2 следует, что кадастровая стоимость по объектам индивидуальной жилой застройки значение кадастровой стоимости в столице субъекта превышает среднее значение кадастровой стоимости по всему субъекту в 3 раза (Республика Дагестан) и в

Таблица 2

Соотношение средних кадастровых стоимостей в субъектах РФ

\begin{tabular}{|c|c|c|c|c|c|c|}
\hline \multirow[b]{3}{*}{ Субъект РФ } & \multicolumn{6}{|c|}{ Средняя кадастровая стоимость, руб./кв.м } \\
\hline & \multicolumn{3}{|c|}{$\begin{array}{c}\text { Многоквартирная жилая за- } \\
\text { стройка }\end{array}$} & \multicolumn{3}{|c|}{ Индивидуальная жилая застройка } \\
\hline & $\begin{array}{c}\text { Столица } \\
\text { субъек- } \\
\text { та РФ }\end{array}$ & $\begin{array}{l}\text { Среднее } \\
\text { по субъ- } \\
\text { екту РФ }\end{array}$ & \begin{tabular}{|c|} 
Отклоне- \\
ние, [2] / [3]
\end{tabular} & $\begin{array}{c}\text { Столица } \\
\text { субъекта } \\
\text { РФ }\end{array}$ & $\begin{array}{c}\text { Среднее } \\
\text { по всему } \\
\text { субъекту } \\
\text { РФ }\end{array}$ & $\begin{array}{c}\text { Отклонение, } \\
{[5] /[6]}\end{array}$ \\
\hline 1 & 2 & 3 & 4 & 5 & 6 & 7 \\
\hline $\begin{array}{l}\text { Белгородская } \\
\text { область }\end{array}$ & 51000 & 33720 & 1,5 & 16500 & 8009 & 2,1 \\
\hline Липецкая область & 42000 & 34012 & 1,2 & 15000 & 8822 & 1,7 \\
\hline $\begin{array}{l}\text { Республика } \\
\text { Ингушетия }\end{array}$ & 17800 & 12169 & 1,5 & 11000 & 8056 & 1,4 \\
\hline Сахалинская область & 59000 & 32012 & 1,8 & 29000 & 13470 & 2,2 \\
\hline $\begin{array}{l}\text { Чеченская } \\
\text { республика }\end{array}$ & 17000 & 13493 & 1,3 & 11000 & 9152 & 1,2 \\
\hline $\begin{array}{l}\text { Карачаево-Черкес- } \\
\text { ская республика }\end{array}$ & 29500 & 21112 & 1,4 & 15900 & 9200 & 1,7 \\
\hline $\begin{array}{l}\text { Нижегородская } \\
\text { область }\end{array}$ & 42800 & 38707 & 1,1 & 32200 & 15180 & 2,1 \\
\hline Республика Дагестан & 31000 & 12169 & 2,5 & 17800 & 5909 & 3 \\
\hline $\begin{array}{l}\text { Кабардино-Балкар- } \\
\text { ская Республика }\end{array}$ & 29900 & 20058 & 1,5 & 14500 & 6740 & 2,2 \\
\hline $\begin{array}{l}\text { Республика Север- } \\
\text { ная Осетия-Алания }\end{array}$ & 29600 & 15530 & 1,9 & 14400 & 8382 & 1,7 \\
\hline
\end{tabular}

${ }^{9}$ ЛисинаН.В., ВахламоваН.А, Кольченко О.В., Южалина О.В.

и др. Аналитические показатели рынка недвижимости.

Н.Новгород: ННГУ им. Н.И.Лобачевского, 2013. - 65с. 
1,2 раза (Чеченская Республика). Кадастровая стоимость объектов многоквартирной жилой застройки в столице субъекта превышает среднее значение кадастровой стоимости по всему субъекту от 1,1 раза (Нижегородская область) до 2,5 раза (Республика Дагестан). Однако среднемесячная заработная плата в столицах субъектов РФ существенно превышает аналогичный показатель в городских и сельских населенных пунктах, поэтому возможно предположить, что налоговая нагрузка для граждан, проживающих в столицах субъектов РФ, будет ниже. Проверим это предположение на примере Нижегородской области.

Оценка налоговой нагрузки на физических лиц по налогу на квартиры, исчисленному на основе кадастровой стоимости, на примере Нижегородской области

Оценим величину налоговой нагрузки с учетом величины прожиточного минимума на каждого члена семьи и с учетом социального вычета по площади в Нижегородской области. При расчете величины налоговой нагрузки были сделаны следующие допущения:

- рассматривается только налог на квартиру (без земельного и транспортного налогов);

- средняя площадь жилого помещения составляет 50 кв. м (по статистике около 82 \% граждан РФ являются правообладателями зданий, помещений, долей в праве общей собственности на здание, помещение, площадью, не превышающей 50 кв. м);

- рассмотрена среднестатистическая семья из трех человек (двое взрослых (оба работающие) и один ребенок), так как, по данным переписи 2002 года, средний размер семьи, домохозяйства в России составляет 2,75 ;

- средняя заработная плата по Нижегородской области берется за 2012 год за вычетом НДФЛ (13\%);

- налоговая ставка принимается максимальной $-0,1 \%$ для жилой недвижимости ${ }^{10}$;

- налоговый вычет по площади ${ }^{11}$ равен 20 кв. м.

Таблища 3

Оиенка налоговой нагрузки на физических лиц по налогу на среднестатистическую квартиру в Нижегородской области

\begin{tabular}{|c|l|c|c|c|}
\hline $\begin{array}{c}\text { № } \\
\text { п/п }\end{array}$ & \multicolumn{1}{|c|}{ Показатель } & $\begin{array}{c}\text { Столица } \\
\text { субъекта }\end{array}$ & $\begin{array}{c}\text { Крупные } \\
\text { городские } \\
\text { населенные } \\
\text { пункты }\end{array}$ & $\begin{array}{c}\text { Сельские } \\
\text { населенные } \\
\text { пункты }\end{array}$ \\
\hline 1 & Среднемесячная заработная плата, руб. (2012 г.) & 21045 & 13252 & 10300 \\
\hline 2 & $\begin{array}{l}\text { Среднемесячная заработная плата с вычетом } \\
13 \% \text { налога, руб. (2012 г.) }\end{array}$ & 18309 & 11529 & 8961 \\
\hline
\end{tabular}

${ }^{10}$ Информационное сообщение Министерства финансов РФ от 31.01.2013 г. «Об основных элементах налога на недвижимое имущество» / - URL: http://www.minfin.ru/ ru/official/index.php?id4=18463

${ }^{11}$ Письмо Министерства финансов и Федеральной налоговой службы России от 06.06.2013 г. № БС-2-11/407. 


\begin{tabular}{|c|c|c|c|c|}
\hline $\begin{array}{l}\text { № } \\
\Pi / \Pi\end{array}$ & Показатель & $\begin{array}{l}\text { Столица } \\
\text { субъекта }\end{array}$ & $\begin{array}{c}\text { Крупные } \\
\text { городские } \\
\text { населенные } \\
\text { пункты }\end{array}$ & $\begin{array}{c}\text { Сельские } \\
\text { населенные } \\
\text { пункты }\end{array}$ \\
\hline 3 & $\begin{array}{l}\text { Среднегодовой доход на семью из } 3 \text { человек } \\
(2 \text { взрослых и } 1 \text { ребенок), руб. }\end{array}$ & 439420 & 276701 & 215064 \\
\hline 4 & $\begin{array}{l}\text { Величина прожиточного минимума: } \\
\text { для трудоспособного населения } \\
\text { для детей }\end{array}$ & $\begin{array}{l}5920 \\
5360\end{array}$ & $\begin{array}{l}5920 \\
5360\end{array}$ & $\begin{array}{l}5920 \\
5360\end{array}$ \\
\hline 5 & $\begin{array}{l}\text { Среднегодовой доход на семью из } 3 \text { человек } \\
\text { ( } 2 \text { взрослых и } 1 \text { ребенок) с вычетом величины } \\
\text { прожиточного минимума на каждого члена } \\
\text { семьи, руб. }\end{array}$ & 233020 & 70302 & 8664 \\
\hline 6 & $\begin{array}{l}\text { Средняя кадастровая стоимость } \\
\text { многоквартирной жилой застройки, руб./кв.м. }\end{array}$ & 42855 & 29079 & 24838 \\
\hline 7 & $\begin{array}{l}\text { Средняя кадастровая стоимость квартиры } \\
\text { площадью } 50 \text { кв.м. в многоквартирном жилом } \\
\text { доме, руб./кв.м (стр.6 * 50) }\end{array}$ & 2142750 & 1453950 & 1241900 \\
\hline 8 & $\begin{array}{l}\text { Величина налога на квартиру в } \\
\text { многоквартирном жилом доме с учетом } \\
\text { социального вычета по площади при ставке } \\
0,1 \%, \text { руб./год (стр.6 * } 30 \text { *0,1) }\end{array}$ & 1286 & 872 & 745 \\
\hline 9 & $\begin{array}{l}\text { Налоговая нагрузка на семью } \\
\text { ( стр.8 / стр.5) }\end{array}$ & $0,55 \%$ & $1,24 \%$ & $8,6 \%$ \\
\hline
\end{tabular}

Для анализа использованы статистические данные, полученные на официальном сайте Территориального органа Федеральной службы государственной статистики по Нижегородской области ${ }^{12}$.

Выводы и рекомендации. В процессе изменения системы налогообложения недвижимости необходимо иметь в виду следующее:

\footnotetext{
12 Официальный сайт Территориального органа Федеральной службы государственной статистики по Нижегородской области. [Электронный ресурс] / - URL: http://nizhstat.gks.ru/wps/wcm/connect/rosstat_ts/nizhstat/ ru/statistics/standards_of_life/
}

Показатель налогового бремени на налогоплательщика является достаточно серьезным измерителем качества налоговой системы, поэтому очевидна необходимость оценки налоговой нагрузки в условиях существенного повышения налоговой базы.

Расчеты показывают, что налоговая нагрузка по налогу на квартиры для жителей г. Н. Новгорода в среднем составит $0,55 \%$; для жителей крупных городских населенных пунктов Нижегородской области- 1,24\%; для жителей сельских населенных пунктов Нижегородской области- 8,6\%. Можно сделать вывод о том, что для жителей сельских 
населенных пунктов это достаточно серьезное налоговое бремя.

Исследуемая модель семьи финансово благополучна. Следовательно, необходимо оценить налоговую нагрузку на различные категории граждан, особенное внимание уделить малоимущим гражданам.

Налоговая нагрузка при максимальной ставке налога будет чрезмерной - это показывают и результаты проекта Международного банка реконструкции и развития «Анализ социально-экономических последствий введения налога на недвижимость» (таблица 2), и проведенная автором исследование. Именно поэтому важно определить ставку налога для смягчения налоговой нагрузки.

В настоящее время конструкция и параметры нового налога известны, кадастровая стоимость определена во всех субъектах РФ, поэтому уже сейчас муниципальные образования могут рассчитать оптимальные ставки налога и оценить налоговую нагрузку.

\section{Библиография:}

1. Анализ социально-экономических последствий введения налога на недвижимость на основе результатов массовой оценки недвижимости: дайджест контракта МБРР № 52-CA-IIIA-QBS [Электронный ресурс]-2011 г. / - URL: http://www.ecsro.ru/uploads/import/doc_ roseestr/2773665/1.pdf

2. Безруков В.Б. Дмитриев М.Н., Пылаева А.В. Налогообложение и кадастровая оценка недвижимости. Монография. Н.Новгород: ННГАСУ, 2011. - 153 с.

3. Безруков В.Б. Социальные аспекты налога на недвижимость. // Налоговая политика и практика. - 2012.-№ 7.-С.12-16.
4. Лисина Н.В., Вахламова Н.А, Кольченко О.В., Южалина О.Н. и др. Аналитические показатели рынка недвижимости. Н.Новгород: ННГУ им. Н.И.Лобачевского, 2013. - 65c.

5. Налог на недвижимость: результаты эксперимента в Великом Новгороде и Твери [Электронный ресурс]: стенограмма «круглого стола» Комитета Совета Федерации по бюджету, 26 янв. 2006 г. // Государственный научно-исследовательский институт системного анализа Счетной палаты Российской Федерации : офиц. сайт. - URL : http://www.niisp.ru/ News/Events/art67.

6. Информационное сообщение Министерства финансов РФ от 31.01.2013 г. «Об основных элементах налога на недвижимое имущество» / - URL: http://www. minfin.ru/ru/official/index.php?id4=18463.

7. Официальный сайт Территориального органа Федеральной службы государственной статистики по Нижегородской области. [Электронный ресурс] / - URL: http://nizhstat.gks.ru/wps/wcm/connect/ rosstat_ts/nizhstat/ru/statistics/standards of_life/

8. Письмо Министерства финансов и Федеральной налоговой службы России от 06.06.2013 г. № БС-2-11/407.

9. Пылаева А.В. Разработка и тестирование системы кадастровой оценки недвижимости в Российской Федерации» // Земля Беларуси.- 2012. - № 1. - С.20-24.

10. Пылаева А.В. Налог на недвижимость: какими должны быть основные параметры // Налоговая политика и практика. - 2013. - № 7. - С. 27-30.

11. Российская Федерация. Законы. О проведении эксперимента по налогообложению недвижимости в городах Великом 
DOI: $10.7256 / 1812-8688.2013 .7 .9345$

При цитировании этой статьи сноска на dоі обязательна

\section{Налоги и налогообложение - №7(109) • 2013}

Новгороде и Твери: Федеральный закон от 20.07.1997г. N 110-Ф3.

12. Шевчук, Л. А. Отчет о результатах эксперимента по введению налога на недвижимость в г. Твери [Электронный pecypc] // - URL: http://old.tchirkounov. ru/articles/print.php?id=210.

\section{References (transliteration):}

1. Bezrukov V.B. Dmitriev M.N., Pylaeva A.V. Nalogooblozhenie i kadastrovaya ocenka nedvizhimosti. Monografiya. N.Novgorod: NNGASU, 2011. - 153 s.

2. Bezrukov V.B. Social'nye aspekty naloga na nedvizhimost'. // Nalogovaya politika i praktika. - 2012.-№ 7.-S.12-16.
3. Lisina N.V., Vahlamova N.A, Kol'chenko O.V., Yuzhalina O.N. i dr. Analiticheskie pokazateli rynka nedvizhimosti. N.Novgorod: NNGU im. N.I. Lobachevskogo, 2013. - 65s.

4. Pylaeva A.V. Razrabotka i testirovanie sistemy kadastrovoy ocenki nedvizhimosti v Rossiyskoy Federacii»// Zemlya Belarusi.- 2012. - № 1. - S.20-24.

5. Pylaeva A.V. Nalog na nedvizhimost': kakimi dolzhny byt' osnovnye parametry // Nalogovaya politika i praktika. - 2013. - № 7. - S. 27-30.

6. Shevchuk, L. A. Otchet o rezul'tatah eksperimenta po vvedeniyu naloga na nedvizhimost' v g. Tveri [Elektronnyy resurs] // - URL: http://old.tchirkounov.ru/articles/ print.php?id=210. 